\title{
In-situ Thermal Treatment of Octacyanometalate-Based Network into $\eta$-Carbides Nanoparticles
}

Thomas Blin $^{1,2}$, Ileana Florea ${ }^{3}$, Frédéric Fossard ${ }^{1}$, Armelle Girard ${ }^{1,4}$, Jean-Sébastien Mérot ${ }^{1}$, Laure Catala $^{2}$, Costel-Sorin Cojocaru ${ }^{3}$, Vincent $\mathrm{Huc}^{2}$ and Annick Loiseau ${ }^{1}$

${ }^{1}$ LEM, UMR 104 CNRS-ONERA, Université Paris Saclay, F-92322, Châtillon, France.

${ }^{2}$ Institut de Chimie Moléculaire et des Matériaux d'Orsay (ICMMO), CNRS, Université Paris-Saclay, Orsay, France.

${ }^{3}$ Laboratoire de Physique des Interfaces et des Couches Minces (LPICM), CNRS, Ecole Polytechnique, IP Paris, 91228 Palaiseau Cedex, France.

${ }^{4}$ Université de Versailles-Saint-Quentin-En-Yvelines (UVSQ), Versailles, France.

Single Walled Carbon Nanotubes (SWCNT) would be an excellent alternative to the silicon technologies in computer and would increase calculation power [1], but their outstanding properties strongly depend on their atomic structures. They can be either semiconducting or metallic, depending on their diameters and chiral angles. The conventional SWCNT growth techniques usually lead to the production of samples with a narrow structure distribution. For decades, researchers have been working on optimizing the growth of SWCNTs, with the aim of obtaining chirality enriched samples. making valuable progress over the years. Among the different synthesis pathways, the use of bimetallic catalyst nanoparticles in chemical vapor deposition (CVD) to synthesize carbon nanotubes is a good alternative for obtaining a selective synthesis and understand they growth mechanism. Theoretical works have demonstrated the importance of carbon solubility in the catalyst nanoparticles on the SWCNT growth mechanism. Furthermore, it has been shown that the presence of carbide within the catalyst could lead to selective SWCNT growth. Recently Hua An et al. [2] managed to realize a selective 1,26 nm diameter SWCNT growth, by using $\mathrm{Co}_{6} \mathrm{~W}_{6} \mathrm{C}$ as a catalyst.

During this study we develop a new pathway to produce a range of carbide bimetallic catalyst nanoparticles called $\eta$-carbides. To obtain these catalysts, octacyanometalate-based networks [3], $\mathrm{Cs}_{2} \mathrm{M}_{7}\left[\mathrm{M}^{\prime}(\mathrm{CN})_{8}\right]_{4} \cdot 6 \mathrm{H}_{2} \mathrm{O}$ with $\mathrm{M}=\mathrm{Co}$ or $\mathrm{Ni}$ and $\mathrm{M}^{\prime}=\mathrm{Mo}$ or $\mathrm{W}$, are synthetized and used as catalyst precursors. Metals $\mathrm{M}$ and $\mathrm{M}^{\prime}$ are linked by $\mathrm{CN}$ bound in a 3D network. We focused on in situ TEM observations of $\mathrm{Cs}_{2} \mathrm{Co}_{7}\left[\mathrm{M}^{\prime}(\mathrm{CN})_{8}\right]_{4} \cdot 6 \mathrm{H}_{2} \mathrm{O}$ catalyst precursors' annealing, between $500^{\circ} \mathrm{C}$ and $800^{\circ} \mathrm{C}$ under inert atmosphere. The experiments are performed within a modified environmental transmission electron microscope-ETEM equipped with a Cs image aberration-corrector, a special sample holder and customized CVD gas sources that allow sending collimated beams of molecules/radicals with different partial pressure. From the experimental point of view the analysis of the recorded images at different temperatures and exposure times allowed us observing a collapse of the 3D network by removal of $\mathrm{CN}$ bounds. These bounds are deteriorated into $(\mathrm{CN})_{2}$ and $\mathrm{N}_{2}$ [4]. A fraction of carbon remains in the system and form carbides phase. This step results in a loss of 40 to $50 \%$ of the sample mass. Precursors turn into nanoparticles at $500^{\circ} \mathrm{C}$ with mean diameter of $6 \pm 2 \mathrm{~nm}$. When the temperature increase, particles coalescence is observed. Final particles mean diameter after the thermal treatment is $8 \pm 2 \mathrm{~nm}$. Our results show two cases of thermal decomposition. In the first case, a mixture of metallic nanoparticles and carbides is observed (ex: $\mathrm{Co}$ and $\mathrm{Mo}_{2} \mathrm{C}$ ). In the other case, we have detected bimetallic carbide nanoparticles (Fig. 2). We highlighted the synthesis of $\mathrm{Co}_{3} \mathrm{~W}_{3} \mathrm{C}$, with TEM imaging, EDX analysis and DRX diagram. $\mathrm{Co}_{3} \mathrm{Mo}_{3} \mathrm{C}$ and $\mathrm{Co}_{6} \mathrm{Mo}_{6} \mathrm{C}$ are also detected with $\mathrm{Cs}_{2} \mathrm{Co}_{7}\left[\mathrm{Mo}(\mathrm{CN})_{8}\right]_{4} \cdot 6 \mathrm{H}_{2} \mathrm{O}$ system. This method open ways to synthesize $\eta$-carbides tuned with a metal composition determined by that of the precursor. Study of these $\eta$-carbides as new catalysts for SWCNT growth are under progress. 


\section{References:}

[1] G Hills, C Lau and A Wright, Nature 572 (2019), p. 595.

[2] H An, A Kumamoto and R Xiang, Science Advances 5 (2019), p. 1.

[3] D Brinzei, L Catala and N Louvain, Journal of Materials Chemistry 12 (2006), p. 2593.

[4] C Aparicio, L Machala and Z Marusak, Journal of Thermal Analysis and Calorimetry 110 (2012), p. 661.

\section{a)}

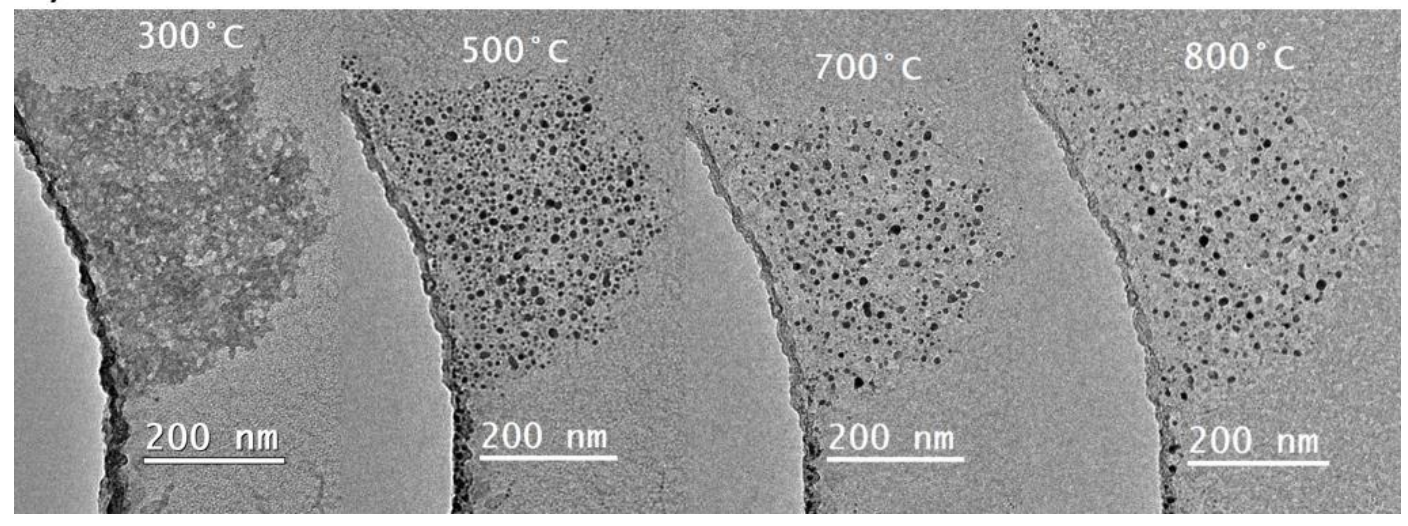

b)
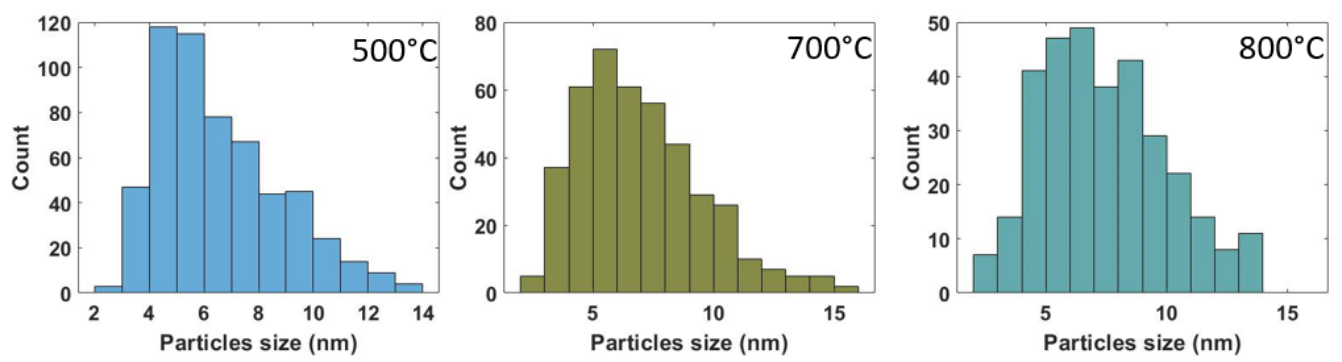

Figure 1. a) Thermal treatment of octacyanometalate-based network $\left(M=C o\right.$ and $\left.M^{\prime}=W\right)$ under inert atmosphere and turn into nanoparticles b) Particles size distribution during thermal treatment.

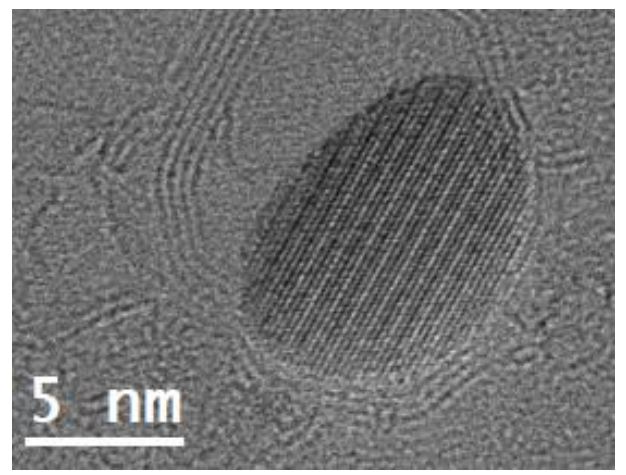

Figure 2. HRTEM imaging of $\mathrm{Co}_{3} \mathrm{~W}_{3} \mathrm{C}$ nanoparticles 